\title{
LETRA DE ESPAÑA. LA NUEVA FÁBRICA TIPOGRÁFICA DE PEDRO DE DISSES (1685)
}

por

\section{Fernando Bouza}

Universidad Complutense de Madrid

RESUMEN: La propuesta becha por Pedro de Disses de fabricar en Madrid moldes, punzones y matrices de imprenta propios es estudiada en relación con las necesidades de la imprenta bispana del siglo xvii a partir de la documentación original presentada ante el Consejo de Castilla en 1685. Se aportan una serie de nuevos datos que permiten conocer mejor a este artífice, estableciéndose su origen borgoñón, su dedicación al arte del marfil y su vinculación con la casa de Juan José de Austria, así como sobre Eugenio de Miranda y Gamboa, encargado por la Diputación de Reinos de prestar apoyo a la iniciativa del borgoñón. La nueva fábrica de 1685 es presentada como una aspiración de los autores naturales que conformaban la particular República de las Letras española, proponiéndose la necesidad de estudiar la aportación de los autores y tipógrafos a la construcción de la memoria de nación.

Palabras Clave: Historia del libro. Tipos de imprenta. Autores, virtuosos y políticos. República de las Letras. Memoria de nación.

ABSTRACT: The innovative printing proposals of Pedro de Disses are studied in relation to the necessities of the seventeenth-century Spanish press on the basis of original documentation from the Council of Castile (1685). A series of new data allows us to know this inventor, establishing his Burgundian origin, his dedication to the art of ivory, and bis links with the bouse of Juan José of Austria, as well as with Eugene de Miranda. The new factory of 1685 is presented as an aspiration of authors belonging to the Spanish Republic of Letters, proposing the need to study the contribution of authors and typographers to the construction of national memory.

KEY WORDS: History of the book. Printing press. 
Alma de la academia veneciana de los Incogniti y su príncipe, el caballero Giovan Francesco Loredano (1607-1661) alcanzó una fama extraordinaria a mediados del siglo xvii gracias al raro ingenio del que hacía gala y de cuya fecundidad y osadía la imprenta daba cuenta con toda celeridad ${ }^{1}$. Una de sus incontables bizarrías pasaba por discurrir si era mayor la infelicidad del cortesano o, por contra, la del amante, pendientes como estaban uno y otro del mínimo gesto de su amada y de su $\mathrm{amo}^{2}$. Impagable parece, igualmente, esa otra disquisición sobre si los príncipes debían desear que sus súbditos fuesen ignorantes o si, a la postre, no harían mejor en quererlos doctos ${ }^{3}$. Su comparación entre academias y repúblicas se revela, en suma, muy elocuente de los afanes de una Europa que caminaba bajo el signo de los virtuosos y los políticos ${ }^{4}$.

Asegura Loredano que los intereses de una academia y los de una república coincidirían en lo fundamental, pues, si aquélla era la «unione di Virtuosi per ingagnar il tempo, e per indagare trà le virtù, la felicità», ésta se podía definir como «unio civium ad foelicitatem». No es extraño, por tanto, que el veneciano concluya que «la medesima Republica non è altro che una scuola ed un' Academia ch'erudisce, ed ammaestra gli huomini»'. La tarea de gobierno viene a presentarse, así, como una labor de marcado carácter instructivo en la que cabe erudire y ammaestrare a los súbditos. Todo ello, repárese, para proporcionales felicidad ${ }^{6}$.

$\mathrm{Ni}$ que decir tiene que proponer la humanísima y mundana felicidad como objetivo de las comunidades eruditas y, también, de las políticas tiene mucho que ver con la reconocida vinculación de los Incogniti vénetos con el pensamiento libertino seiscentista ${ }^{7}$. En algunos de sus libros, como en las dos series de los Scherzi geniali, Loredano utiliza las epístolas preliminares para despedirse del

\footnotetext{
1 Menegatri, Tiziana: Ex ignoto notus. Bibliografia delle opere a stampa del Principe degli Incogniti: Giovan Francesco Loredano, Padova, 2000. Este trabajo se inscribe dentro del Proyecto BHA200203328 financiado por la Dirección General de Investigación del Ministerio de Educación y Ciencia.

2 «Se sia piu infelice il Corteggiano o l'Amante», cito por LOREDANO, Giovanni Francesco, Bizarrie academiche (Parte prima), [1638], Venetia, 1684, pp 184-189.

3 "Se sia meglio che'l Prencipe habbia i sudditi dotti, o ignoranti», cito por LOREDANO, Giovanni Francesco, Bizarrie academiche (Prima seconda), Venetia, 1684, pp. 97-104.

4 Véanse Koenigsberger: Helmut G., Politicians and virtuosi. Essays in early modern history, London, 1985; y Miller, Peter N., Peiresc's Europe. Learning and virtue in the Seventeenth Century. New Haven-London, 2000.

5 "Qual cosa pregiudichi maggiormente alla conservatione dell'Accademie», Bizarrie... (Parte primat, cit., pp. 137-138.

6 Cfr. Álvarez De MiRanda, Pedro: Palabras e ideas. El léxico de la Ilustración temprana en España (1680-1760), Madrid, 1992, pp. 271-290.

7 Miato, Monica: L' Accademia degli Incogniti di Giovan Francesco Loredan, Venezia (16301661), Firenze, 1998.
} 
desconocido lector con un expresivo «vive felice». En esos paratextos le advertirá, también, que emplea palabras como deidad, adorar o angélico conforme al uso del siglo y no a la intención de la fe, porque «lo scrivere per ischerzare non pregiudica al debito del credere» ${ }^{8}$.

Esta esclarecedora epístola «A chi legge» no aparece, sin embargo, en la edición española de los Scherzi que salió de las prensas valencianas de Antonio Bordazar en 1731 siguiendo una versión de Miguel Egual9: También se tomó entonces la decisión de suprimir dos de las «declamacioncillas» que el veneciano había dedicado a los amores de Caracalla y a la lascivia de Friné por parecer en exceso perniciosas, como explica Gregorio Mayans en un interesante juicio que antecede al texto principal de la obra ${ }^{10}$. Menos escrúpulos tuvo Eugenio de Miranda y Gamboa cuando sí incluyó el "Antonino Caracalla Amante» en su traducción de la primera parte de los Scherzi que apareció en Madrid en 1688 como Burlas de la fortuna en afectos retóricos ${ }^{11}$.

No obstante, en esta ocasión aquella epístola en la que Loredano se ponía cautamente a resguardo advirtiendo cómo debían entenderse algunos términos que tomaba del léxico de la fe fue sustituida por otra quizá no menos sorprendente. En el «Al letor» de las Burlas de 1688 se anunciaba expresamente que, dejando al lado el gusto de algunos que sabrían encontrar un poco de felicidad en los casos de fortuna allí evocados ${ }^{12}$, lo que realmente importaba del libro no era su contenido, sino «lo material de la Impressión, que es el fin porque sale a la luz». Lo que es más, aquella traducción se presentaba como la obra impresa a la que le cabía el honor de ser la "Primogénita de estos Reynos», pues ella y sólo ella se había «fabricado en esta Corte desde el primer Instrumento» ${ }^{13}$.

8 Loredano, Giovanni Francesco, Scherzi geniali. Parte prima [1632], Macerata, 1644, "A chi legge». Cfr. CAVAILlÉ, J.P.: Dis/simulations. Jules-César Vanini, François La Mothe Le Vayer, Gabriel Naudé, Louis Machon et Torquato Accetto : religion, morale et politique au XVIIe siècle, Paris, 2002.

9 LOREDANO, Giovanni Francesco: Declamaciones geniales (...) traducidas de idioma italiano en español $i$ adicionadas con varios sonetos por Miguel Egual, Valencia, 1731.

10 Esta edición incluye la serie completa de los scherzi con excepción de «Antonino Caracalla Amante", de la primera parte, y "Friné Lasciva», de la segunda, según explica Mayans en su "Juicio" firmado en Valencia a 28 de marzo de 1731. En carta a Roque Deville (Valencia, 15 de diciembre de 1730), D. Gregorio anunciaba: «Un amigo mío [Egual] ha traducido de italiano en español las burlas de genio de Francisco Loredano. La traducción es superior en el lenguage i elegancia al mismo original. Estas declamacioncillas paran en mi poder i no se malograría el trabajo de imprimirlas", MAYANS Y SISCAR, G.: Epistolario. XII. Mayans y los libreros, Transcripción y estudio preliminar de Antonio Mestre, Valencia, 1993, p. 290.

11 LOREDANO, Giovanni Francesco: Burlas de la fortuna en afectos retóricos de el Loredano, tradución del toscano a nuestro vulgar por D. Eugenio de Miranda y Gamboa, Madrid, 1688.

12 Los Scherzi se presentan como una colección de sublimes y pasionales casos de los que se habría ocupado Loredano en las sesiones de su academia veneciana. Las fortunas tratadas en su primera parte eran las de Cicerón, Séneca, Marco Antonio, Aquiles, Seyano, Caracalla, Agripina, Sisigambis, Popea, Lucrecia y Oenone.

13 «A quien no agradare, conténtese con lo material de la Impressión, que es el fin porque sale a la luz», Burlas de la fortuna..., cit., "Al letor», sin foliar. Cfr. BOUZA, Fernando: "Aun en lo mate- 
Primogenitura tan particular le correspondería a las Burlas de la fortuna de 1688 en atención a que las matrices, los punzones y los moldes tipográficos empleados, todo desde el primer instrumento, habían sido fabricados en Madrid por un "gran artífice» cuyo nombre no se desvelaba en la obra. Con todo acierto, Don W. Cruickshank lo identificó como Pedro Disses hace ahora un cuarto de siglo $^{14}$.

Este autor llamó la atención sobre un pasaje de las Memorias políticas y económicas de Larruga en el que se recogía que Disses había venido a la corte «para establecer fábrica de punzones y matrices para executar por sí las fundiciones y enseñar todas las operaciones de este arte a quien quisiese instruirse en ellas» ${ }^{15}$, así como que sus esfuerzos se habían plasmado en la edición de las Burlas de 1688 amparado por Antonio de la Vega y Eugenio de Miranda, "practicando quanto sabía en la propia habitación del último de sus bienhechores» ${ }^{16}$.

Por tanto, quien había sido el traductor de Giovan Francesco Loredano se había ocupado también de proteger a Disses y, quizá, sus propias casas habían servido para imprimir las Burlas, un proceso que, como se dice en su epístola "Al letor», se había hecho aceleradamente "sin el beneficio del tiempo» ${ }^{17}$. Curiosamente, ese ambiente de moldes y punzones en la habitación del caballero Miranda y Gamboa no desentonaría mucho con el espíritu del académico veneciano y sus propuestas de mostrar la coincidencia entre los objetivos de una academia de sabios y una república de políticos.

Tres años después de la edición de esta obra, en 1691, el «gran artífice» del que hablaban las Burlas presentó un memorial rogando que se le hiciera merced de un plaza en la guardia palatina de los arqueros de corps $^{18}$. Gracias a esta petición, acompañada de los habituales documentos genealógicos, es posible saber que quien entonces se hace llamar «Don Pedro de Disses»19 era natural

rial del papel y ynpresión». Sobre la cultura escrita en el siglo de Gracián», en Ángel San Vicente (edr.), Libros libres de Baltasar Gracián. Exposición bibliográfica, Zaragoza, 2001, pp. 11-50.

14 CRUICKSHANK, Don Willian: «Some aspects of Spanish book-production in the Golden Age», en The Library (Oxford) 31-1 (1976), pp. 1-19; y "The types of Pedro Disses, punchcutter", en Journal of the Printing Historical Society (London) 17 (1982-1983) pp. 72-91.

15 LARRUGA, Eugenio: Memorias políticas y económicas sobre los frutos, comercio, fábricas y minas de España, vol. III, Madrid, 1788, p. 309. El artífice era citado aquí como Diego Disses y así lo llamaba todavía Cruickshank en su «Some aspects...», cit., pp. 14-15:

16 Idem, id, p. 310.

17 Burlas de la fortuna..., cit., "Al letor», sin foliar. El pie de imprenta de las Burlas indica únicamente «Madrid, Año 1688".

18 Archivo de Palacio, Madrid [AP], Sección Histórica, Tropas de la Casa Real, Archeros de la Noble Guarda de Corps, legajo 163, expediente «Disses, Pedro de» [1691], para el memorial; y legajo 168 para las pruebas, Papeles que pressentó Pedro Dizes pretendiente a una plaza de archero sobre que se ymformó a su Excelencia [1691]. No hay testimonio documental de que alcanzase la merced solicitada.

$19 \mathrm{El}$ nombre del artífice lo hemos llegado a encontrar escrito de tres formas distintas: Pedro de Disses, Pedro Disses y Pedro Disse. Seguiremos la primera de ellas porque fue la utilizada por el propio artífice en el memorial de 1691.

Hispania, LXV/3, núm. 221 (2005) 957-972 
de la localidad de Saint Claude, en el Franco Condado, donde había sido bautizado en $1645^{20}$, así como que había servido a Juan José de Austria «cerca de 14 años» y que había asistido «en todos los viages que se han ofrecido», entre ellos el de la Jornada Real a Aragón. El borgoñón, en suma, solicitaba la citada merced en atención a que:

«[...] cerca de 13 años (sic) ha travajado en diferentes obras en el Real Palacio en presencia de Vuestra Magestad y desde este tiempo hasta agora se ha empleado en las fábricas de la ympressión y la de los alambres para la seda de horden de Vuestra Magestad, la qual dicha fábrica de la impressión no ha podido fenezer por las razones que a Vuestra Magestad tiene representadas diferentes vezes».

La expresa mención de D. Juan José, así como las referencias a que se había ocupado tanto en la fábricas de la impresión como en una de alambres para la seda, permitirían vincular a Disses con las distintas iniciativas que se suelen poner en la órbita de la Junta de Comercio y para las que, como muy bien se sabe, se reclutaron artesanos y artífices foráneos ${ }^{21}$. No obstante, la relación con el de Austria parece haber sido más estrecha, pues, si creemos al propio Disses en su memorial, se habría prolongado durante unos catorce años ${ }^{22}$.

Hay que recordar que entre las muchas dignidades que llegó a acumular el hijo de Felipe IV se encontraba la de titular de la abadía de Saint Claude ${ }^{23}$, precisamente la localidad natal de Disses. Por otra parte, la talla del marfil era una manufactura de honda raigambre en esa zona del Franco Condado de la que fueron originarios numerosos artistas que emigraron hacia distintos lugares del sur de Europa ${ }^{24}$, en concreto los llamados Claudio y Pedro Disse que estuvieron al servicio de Juan José como ayudas de la tapicería y escultores torneros, realizando trabajos de eboraria para su Alteza en Aragón a comienzos de la década de $1670^{25}$.

20 Fue hijo de Nicolás Disses y Humberta Fusier, siendo bautizado el 6 de octubre de 1645 en Saint Claude.

21 KAMEN, Henry: La España de Carlos II, Barcelona, 1981, pp. 122-132.

22 El memorial de Disses indica expresamente: «[...] dize que ha servido a su Alteza el sereníssimo Señor Don Juan de Austria cerca de 14 años», lo que permitiría remontar su vinculación a la segunda mitad de la década de 1660, teniendo en cuenta que D. Juan José falleció en 1679.

23 D. Juan José fue el nonagésimo segundo titular de la abadía. Véanse Gallia.Christiana in provincias ecclesiasticas distributa, vol. IV, Parisiis, 1739, p. 253; y DUNOD DU CHARNAGE, FrançoisIgnace: Histoire des Séquanois et de la province séquanoise, des Bourguignons et du premier royaume de Bourgogne, de l'église de Besançon jusque dans le vie siècle et des abbayes nobles du comté de Bourgogne, vol. I, Dijon, 1735 , p. 119.

24 Véase EstellA, Margarita: La escultura barroca de marfil en España. Las escuelas europeas y las coloniales, Madrid, 1984.

25 GonZález ASEnJo, Elvira: Don Juan José de Austria y las artes: 1629-1679, Madrid, 2005. Agradezco a la autora estos datos, así como la bibliografía sobre los artistas del marfil en la España del xvii, que me ha facilitado con su amabilidad y erudición habituales. Que Disses figure en la

Hispania, LXV/3, núm. 221 (2005) 957-972 
El trabajo sobre marfil parece haber sido el principal y primer oficio de Pedro de Disses. Así, entre las pruebas que adjuntó en 1691 para abonar la citada concesión de una plaza de arquero figura un diploma del nuncio Savo Millini en el que se le presenta como «D. Pedro Disse escultor oriundo de la ciudad de San Claudio en la Contea de Borgoña» ${ }^{26}$. Este hecho permitiría identificarlo con el artífice del mismo nombre y lugar de origen que formaba parte de una compañía de artistas del marfil que estuvo activa entre Madrid y Granada a mediados de la década de $1660^{27}$. La compañía se vio envuelta en un proceso por contrabando de marfil y acabó disolviéndose en Madrid en 1666 mediante una carta de finiquito que firma, precisamente, un Pedro Disses ${ }^{28}$.

Por el diploma de Savo Millini, de 1681, no cabe duda que el artífice de la nueva fábrica de punzones y matrices de la corte era también escultor, lo que sumado a los otros testimonios sobre eborarios borgoñones originarios de Saint Claude activos en España y del mismo nombre permitiría concluir que se trataba de un escultor sobre marfil. Así, del taller y el torno de eboraria, y no de la ceca o de la platería, Disses habría pasado al trabajo con metales, tanto en las fábricas de la impresión como en la de alambres para la seda, como él mismo dice en su memorial de 1691. Lo minucioso de este oficio no estaría lejos del detalle necesario al, digamos, diseñador tipográfico, pero esta circunstancia quizá explique que sus productos no alcanzasen, a la postre, una extraordinaria perfección.

Sea como fuere, en octubre de 1685, la Diputación de los Reinos de Castilla había representado ante la Majestad del rey Carlos II que el borgoñón, calificado sólo de «maestro del arte de imprimir», había ofrecido «dar caracteres de todos géneros de letras dentro de diez meses para que con este motivo no se saquen fuera destos Reynos las impressiones» ${ }^{29}$. Vista en el Consejo de Castilla por decreto real dicha representación y considerando que podría ser de conveniencia para «la utilidad pública», se ordenó que el consejero Isidro de Camargo reuniese en su casa a los impresores para «examinarla enteramente» ${ }^{30}$.

nómina de la tapicería ayudaría a explicar la mención (supra) de que había estado presente en las jornadas y viajes.

26 Se trataba de la concesión de la dignidad pontificia de Caballero de la Milizia Aurata, firmada por Millini en Madrid, a 22 de octubre de 1681, Papeles que pressentó Pedro Dizes pretendiente a una plaza de archero..., cit.

27 ESTELlA, M.: La escultura barroca de marfil en España..., cit., vol. II, pp. 110-111. Los miembros de la compañía eran Pedro Disses, Claudio David y Juan Girod.

28 La transcripción de la carta de pago y finiquito otorgada por Pedro Disses, Madrid, 1 de junio de 1666, fue publicada en Estella, Margarita, y BARRIO MOYA, José Luis: «Actividad documentada en Andalucía de los escultores en marfil del Franco Condado y obras de otros escultores posiblemente de la misma procedencia», en Revista de arte sevillano (Sevilla) 3 (1983) pp. 17-25. Si se tratase del mismo personaje, el Disses de las Burlas habría estado ya en España a mediados de la década de 1660 , contando para entonces unos veinte años de edad.

29 Representación de la Diputación de Reinos, Madrid, 11 de octubre de 1685, Archivo Histórico Nacional, Madrid [AHN], Consejos suprimidos, legajo 7157, 69.

30 Consulta del Consejo de Castilla, Madrid, 16 de noviembre de 1685, AHN, Consejos suprimidos, legajo 7157, 69. Para ésta y las siguientes citas en el texto. 
En esa primera junta, que debió celebrarse el 19 de octubre de $1685^{31}$, los impresores convocados «asentaron todos quán sin maestros de este arte está España» y como, por esta causa, «no están las imprentas surtidas de todos los géneros de letras de que necesitan para poder correr generalmente en la impresión de los libros». De esta forma, se insistía una vez más en que las carencias materiales, como aquí era la falta de letra o, en otros casos, la calidad del papel $\mathrm{u}$ otras dificultades ${ }^{32}$, entorpecían el pleno desarrollo de la imprenta hispana.

La mayor parte de los convocados por Camargo, no obstante, dijeron no conocer ni a Disses ni haber visto sus instrumentos por lo que pidieron que se presentase ante ellos y «que mostrase las matrices y punzones y los moldes en que se bazía la letra y los dibujos que tenía hechos, pues sin vista de esto no podían dezir su sentir». De esta forma, Pedro de Disses fue llamado a una segunda junta de impresores el 24 de octubre 33 ante la que presentó «todos los instrumentos y las muestras que tiene executadas».

Una vez vistos y examinados, los impresores se mostraron satisfechos y declararon su censura y parecer al respecto, que pasaba por afirmar:

«[que] con poca rreformación tenían los punzones todas las calidades de perfeción que se requiere, pero hera menester que fabricase en forma según la muestra que los maestros de imprenta entregaron, que se pone en las reales manos de Vuestra Majestad, y se conformaron todos en que sería obra de grande conbeniencia y de utilidad conozida, pues podría correr generalmente en España sin necesitar de recurrir a otros Reynos, pero devían dezir por el conocimiento que tienen de Pedro Disse que socorriéndole con el caudal que pide sería mui necesario que éste corriese por mano de la Diputazión adonde affianzase el tiempo en que ha de executar lo que offreze, pues de lo contrario se seguiría el no lograr lo que se intenta por divertirse entendiendo en differentes artes y con esta dilazión no llegar a perfección lo que puede ser tan útil».

A la luz de este parecer de los impresores madrileños, el Consejo de Castilla elevó al rey una consulta por la que proponía que se socorriese a Pedro de Disses con la cantidad que pedía, que ascendía a cuatro mil ducados, pero no directamente, sino a través de la Diputación de Castilla, encargándose ésta de costear los materiales y el trabajo del artífice, «corriendo a su cuidado el asegurar el tiempo dentro del qual execute los punzones necesarios, según la muestra que los maestros han dado» ${ }^{34}$.

31 Así parece desprenderse del Memorial sobre el arte de imprimir de Lucas Antonio de Bédmar, uno de los convocados, que dio a conocer Cruickshank, "The types of Pedro Disses...», cit., pág. 72.

32 Véase PÉLIGRY, Christian: «Les dificultés de l'édition castillane au xviie siècle à travers un document de l'époque» en Mélanges de la Casa de Velázquez (Paris) 13 (1977) pp. 257-284.

33 La fecha también la proporciona Bédmar, «The types of Pedro Disses...», cit., pág. 72.

34 La consulta de 1685 se acompañó tanto de las muestras que Pedro de Disses había presentado para que fueran examinadas por los impresores como de la que éstos entregaron para que, según ella, el artífice fabricase sus punzones. MVESTRA DE LOS / CARACTERES, YLETRAS / DE 
Además de ese censura y parecer colectivo del que se hacía traslado en la consulta del Consejo, los impresores Julián de Paredes y Lucas Antonio de Bédmar habrían elevado también sendos papeles en relación a la propuesta del borgoñón. Don W. Cruickshank publicó el Memorial sobre el arte de imprimir del segundo, fechado en Madrid a 28 de octubre de 1685, apenas cuatro días después de que Disses se hubiese presentado ante los impresores ${ }^{35}$. No se conserva, sin embargo, ejemplar del que habría dado Paredes «en Nombre de todos los Maestros, en que dize. su Parecer a su modo: el qual entregó el mismo Día 24 de Octubre por la Tarde (que fue la del Reconocimiento de las Muestras [...])» y que Bédmar descalifica como «poco ajustado» por haber sido redactado antes de que Pedro de Disses se presentase ante los impresores convocados por Camargo ${ }^{36}$.

Junto a una contundente carga contra Julián de Paredes y una reivindicación de su propio protagonismo en el negocio, Lucas Antonio de Bédmar se muestra entusiasta partidario de la nueva fábrica que encarece por su utilidad y necesidad, aunque también señala que debería ser en parte perfeccionada. Este impresor nos proporciona, además, la siguiente descripción de las muestras presentadas por el borgoñón: una primera se compondría « de seis Moldes, que ha hecho para fundir diferentes Caracteres»; otras tres corresponderían a «tres géneros diversos de Letras grandes Titulares, que se llaman: Dos Líneas de Parangona: Dos Líneas de Texto, y Dos Líneas de Letura, siendo el quarto Género un Adorno de flores»: la sexta sería una muestra de atanasia redonda y la séptima «es el de Texto Cursiva [sic], y Redondo» ${ }^{37}$.

De los materiales presentados originalmente por Pedro de Disses en 1685 parecen haberse conservado cinco piezas en el Archivo Histórico Nacional ${ }^{38}$ : tres muestras de géneros de letras grandes titulares (parangona, texto y lectura) y dos que se califica de demostraciones. Una de éstas, fechada en Madrid a 17 de mayo de 1685 , presenta un texto de lo más elocuente:

«CONTINÚA la DIPUTACIÓN de los REYNOS DE CASTILLA, y LEÓN, la Demostración de PUNZONES, MATRIZES, MOLDES, y LETRA, en el presente Carácter de Texto, juntamente con las Dos Líneas de PARANGONA, las de TEXTO, y las de Letura; todo fabricado en esta CORTE, para la mejor introducción del Divino Arte de Imprimir: Mantenido en estos REYNOS (hasta el Día de oy) de Alimentos Estrangeros, que embían la Letra vaziada, y las Matrizes que desechan, en gravíssimo perjuizio de los Vassallos de ellos: (De cuya Nueva Fábrica resultarán Instrumentos, que dispongan un Movimiento continuo para la Perpetui-

\footnotetext{
LA IMPRENTA REAL. / Passóse de S. Francisco à la Carrera de S. Gerónimo, junto à N.S. de la Soledad, S.I. [Madrid], n.a. [1685]. AHN, Consejos suprimidos, legajo 7157, 69. La Muestra incluye misal, parangona, texto, atanasia, lectura, breviario y glosa.

35 «The types of Pedro Disses...», cit., pp. 72-75.

36 Idem, p. 73.

37 Idem, p. 74.

38 AHN, Consejos suprimidos, legajo 7157, 69. Agradezco a la Profesora Mercedes Fernández Valladares y al Dr. Valentín Moreno Gallego su inestimable asesoramiento en este punto.
} 
dad:) Siendo PRESIDENTE DE CASTILLA el Excelentíssimo señor CONDE DE OROPESA: De quien espera la Orden, para executar lo que más convenga» ${ }^{39}$.

La Diputación de Reinos se presentaba, así, como responsable última de la nueva fábrica tipográfica de Pedro de Disses, cuyos instrumentos generarían «un movimiento continuo para la perpetuidad» a través de «la mejor introducción del divino arte de imprimir». Pero es hora de volver a las Burlas de la fortu$n a$, cuya autoproclamada primogenitura tipográfica se explicaría porque, como campea en su portada, fue la primera obra que «se da a la estampa, en las pruebas de nuevos caracteres, fabricados en esta Corte, a fin de establecer Impressiones propias en estos Reinos".

En la dedicatoria al entonces todopoderoso Manuel Joaquín Álvarez de Toledo, Conde de Oropesa, que abre las Burlas, Miranda y Gamboa expone con claridad por qué la Diputación se había interesado por la cuestión y cómo él mismo había pasado a ocuparse de la empresa de Disses. Dice el traductor del Loredano ${ }^{40}$ que:

«El primer instituto de la Diputación de estos Reynos, se dedica [...] a suplicar a su Magestad la observancia de las condiciones de los servicios, muros los más fuertes en su seguridad, y conservación. Y siendo el mayor cuydado detener en sí los tesoros, que la industria, y naturaleza les ha franqueado, y evitar en algún modo la continua assechança, y ardiente saña de estrangeros, que avaros de tal felicidad, con aparentes, e inútiles géneros, y engaños desangran a esta Monarchía la verdadera sustancia, que sale por sus Puertos en peremnes raudales, no de arenas, sino de lluvias de oro. Y pendiendo del descuido, y falta de aplicación, propio atributo de Españoles, que manteniéndose de la generosidad, y alteza de espíritu, desprecian lo material; hizo más preciso el cuydado de la ampliación de

39 [Demostración de punzones, matrices, moldes y letra en el carácter de texto presentada por Pedro de Disses] $A$ bonra, y gloria de la Santíssima Trinidad, S.l.. [Madrid]: s.a. [1685], AHN, Consejos suprimidos, legajo 7157,69. La segunda Demostración está fechada en Madrid, 18 de octubre de 1684.

40 A caballo entre Austrias y Borbones y, también, entre asientos y oficios, el cursus vitae del zamorano Eugenio de Miranda y Gamboa está íntimamente vinculado al servicio real y a su hacienda. Su lugar de nacimiento se conoce gracias a las pruebas realizadas en 1722 para el matrimonio de su nieta María de Álamos Miranda con Antonio Curiel, AHN, Órdenes Militares, Calatrava, Casamientos, Exp. 20. Casó con Josefa de Gamboa, siendo padres de Manuela de Miranda y Gamboa, esposa del Marqués de Villasinda, Juan Antonio de Álamos y Quiñones. En 1685, obtuvo la merced de una plaza de gentilhombre de boca, aunque sin gajes ni casa de aposento, por haber «conqurrido con su boto en la última prorrogación de Millones», AP, Personal, 686-10. Inmediatamente después de la impresión de sus Burlas, cuya tasa está firmada en Madrid, a 22 de mayo de 1688, ( cit., sin foliar), en junio de 1688 tomó posesión como corregidor de Carmona, pasando después a desempeñar otros tres corregimientos (Úbeda y Baeza, Jaén y Antequera) y llegando a ser superintendente y administrador general de la renta del tabaco y asentista del mismo, además de gentilhombre de cámara, consejero de Hacienda ad bonorem y supernumerario. Datos tomados de la Base de Datos FICHOZ (CNRS). Agradezco a la Profesora Teresa Nava su amabilidad al franquearme las noticias de este importantísimo instrumento para la investigación. 
Artes y Fábricas, obligando al Reyno, que en las nuevas concessiones se estipulasse, y precaviesse la mejor forma de adelantarse, y en igual grado a los Diputados repetir las instancias a su Magestad.

A este intento (hallándome en la ocupación deste ministerio) ofreció un gran Artífice labrar en esta Corte todos los instrumentos, que dan crédito, estimación, y valor a las impressiones estrangeras, y que faltan en las propias (y frando a la experiencia el acierto) se me encargó la disposición» ${ }^{41}$.

El apoyo a la iniciativa de fabricar punzones, matrices y moldes en la corte de la Monarquía se presentaba como una medida de carácter mercantilista tendente a evitar su empobrecimiento poniendo trabas al comercio de libros extranjeros por lo que éste suponía de salida de caudales. Sin duda, la Diputación de Reinos cumplía, así, con uno de sus cometidos fundamentales llegados los años finales del siglo xvii, dando muestras de sus competencias sobre las actividades comerciales y productivas ${ }^{42}$.

Por supuesto, la preocupación por el impacto de las impresiones foráneas se puede detectar desde mucho antes. Lo hace, por ejemplo, en diferentes disposiciones legales que pretendían que los «autores naturales» no pudieran llevar a imprimir sus obras «fuera del reino», así como en un buen número de textos surgidos en torno a la consideración fiscal del libro impreso, la condición liberal o artesana de la imprenta y a los pleitos de libreros y maestros tipógrafos ${ }^{43}$. No parece que pueda ser casual que el reinado de Carlos II asista a la edición de textos tan significativos como la Institución y origen del arte de la imprenta de Alonso Víctor de Paredes (c. 1680) o el Discurso legal, bistórico y político en prueba del origen, progressos, utilidad, nobleza y excelencias del arte de la imprenta de Melchor de Cabrera (1675), títulos ambos muy cercanos en el tiempo a la iniciativa de Pedro de Disses.

Al haberla hecho suya la Diputación de Reinos, con esta propuesta se da un paso más allá en lo que tiene de expediente práctico no ya de importación de letrería, sino de su fabricación en el mismo corazón de la Monarquía, anticipando, de hecho, algunas iniciativas de época borbónica mucho mejor conocidas $^{44}$. De nuevo, Eugenio de Miranda nos deja un importante testimonio de la plena conciencia de cuánto podía suponer la imprenta para una Monarquía:

41 Miranda y Gamboa, Eugenio: Dedicatoria al Conde de Oropesa, Burlas de la fortuna..., cit., sin foliar.

42 Castellano, Juan Luis: Las cortes de Castilla y su Diputación (1621-1789). Entre pactismo y absolutismo, Madrid, 1990, pp. 85-112 [«La Comisión de millones y la Diputación del Reino en el último tercio del siglo xvii»]

43 Sobre esta literatura normativa, apologética y judicial, que no cesa de crecer, véase REYES, Fermín de los, El libro en España y América. Legislación y censura (siglos xv-xviii), vol. I, Madrid, 2000, pp. 266-288.

44 Véanse, entre otros, La imprenta en Valencia en el siglo xviii. Antonio Bordazar de Artazu, Valncia, 1997; MOLL, Jaime: "Introducción" en Muestras de los nuevos punzones y matrices para la letra de imprenta executados por orden de S.M., II vol., Madrid, 1988; «La Biblioteca Real y los juegos de ma-

Hispania, LXV/3, núm. 221 (2005) 957-972 
«Es el Arte de la Imprenta Divino, y milagroso en lo humano, pues dispone supla uno el trabajo de mil; instrumento que franquea la preciosa Margarita; la Antorcha de más explendores; la luz sin Ocaso; nueva regeneración del hombre, pues le distingue de los brutos en tantos libros cuerpos con alma, que le hazen capaz de todas las Ciencias, assegurando en su mano, no sólo el Cetro del Orbe, sino el dominio de los Astros. Es la fragua de la Milicia Literaria, el nervio de los talentos; Antídoto contra el veneno de los vicios, y el escudo, y defensa en todo el concierto Éthico y Político, sobre que se afirma el estado, y duración de las Monarchías» ${ }^{45}$.

Pese a su brevedad, la alabanza de la tipografía que aquí entona Miranda se encuentra entre las más singulares que podemos encontrar en el Siglo de Oro y, quizá también, en la Ilustración. Como tantos otros, comienza por reconocer lo ingenioso y sorprendente de su mecánica, en la que el trabajo de uno sustituye al de mil, pero, además, atribuye a la imprenta la categoría de vía segura que, iluminando al hombre como antorcha y luz sin ocaso, conduce hacia el conocimiento de todas las ciencias. Ventajoso instrumento de la sabiduría humana y regeneradora de su condición, la imprenta permite al hombre dominar la naturaleza terrestre del orbe y la sideral de los astros, creando una milicia literaria de autores que sólo pueden mostrar convenientemente su talento gracias a ella. En suma, la tipografía se revela para Miranda y Gamboa la herramienta necesaria y útil de la construcción comunitaria sobre la que, en último término, descansarían las Monarquías, cuyo estado y duración le serían deudoras pues, al animar los estudios y preservar de los vicios, mantendría «el concierto Éthico y Político» sobre el que aquéllas descansaban.

Sin duda, es enorme la deuda de este elogio con otros textos que encomian la imprenta como un don que sólo cabía calificar de divino, empezando por el Discurso de Melchor de Cabrera, que le es tan cercano en el tiempo. Pero Eugenio de Miranda no sólo parece preocuparse por el enaltecimiento de la imprenta como un arte liberal, sino que, yendo más allá que Cabrera y, por ejemplo, su insistencia en las personas reales como tipógrafos, propone una Monarquía asentada sobre la imprenta, quizá porque su relación con la nueva fábrica de Disses se haya desarrollado al amparo de un organismo de naturaleza política tan particular como la Diputación de Reinos.

En el memorial presentado en 1691 para la concesión de una plaza de arquero, que ha ofrecido importantes noticias biográficas, el propio Pedro de Disses reconocía que «la qual dicha fábrica de la impressión no ha podido fene-

trices existentes en Madrid alrededor de 1760" en Boletín de la Asociación española de archiveros, bibliotecarios, museólogos y documentalistas (Madrid) 42 (1992), pp. 9-21; y «Juan Gómez de Morales, fundidor de tipos", en De la imprenta al lector. Estudios sobre el libro español de los siglos xvi al xviii, Madrid, 1994, pp. 119-132; y REYES, Fermín de los: «Antonio Espinosa de los Monteros, ebuen grabador de letras de imprenta?» en Pliegos de Bibliofilia (Madrid) 11 (2000), pp. 71-75.

45 Miranda y Gamboa, Eugenio: Dedicatoria al Conde de Oropesa, Burlas de la fortuna..., cit., sin foliar. 
zer por las razones que a Vuestra Magestad tiene representadas diferentes vezes» ${ }^{46}$. No nos ha sido posible determinar cuáles fueron esas razones que dificultaron la nueva fábrica del borgoñón y que impidieron su realización completa, a no ser el propio cursus vitae de Eugenio de Miranda, cuya trenza de oficios lo alejó de la Diputación, llevándolo a ocupar distintos corregimientos andaluces $^{47}$.

Sin embargo, al evaluar el calado de esta iniciativa, Jaime Moll ha destacado que ésta sirvió para que se «desempolvasen» las matrices que Carlos II había hecho traer de Flandes o de Holanda para los jesuitas del madrileño Colegio Imperial, las cuales empezaron a ser alquiladas para la fundición de tipos, vencida la renuencia que la Compañía habría mostrado hasta entonces ${ }^{48}$. Por su parte, D.W. Cruickshank fue, con todo detalle, recogiendo los testimonios del uso por parte de distintos impresores de Madrid, Sevilla, Écija o La Habana de los tipos propuestos por Disses y empleados por vez primera en las Burlas de la fortuna ${ }^{49}$, demostrando una difusión considerable que habría empezado con la compra de matrices y punzones de Disses que Bernardo de Villadiego habría efectuado ya el mismo año de su presentación ante el Consejo ${ }^{50}$.

Aunque el borgoñón había ofrecido en 1685 «dar caracteres de todos géneros de letras dentro de diez meses» ${ }^{51}$, las Burlas de la fortuna se convirtieron en el fruto primogénito y casi único de su nueva fábrica. En 1688, «deseando - como se dice en la dedicatoria a Oropesa- llegasse a mano de V. Exc. algún diseño de lo que se havía executado", Miranda había decidido imprimir con los tipos de Disses la traducción que él mismo había realizado de los Scherzi geniali ${ }^{52}$.

La elección de una obra de Giovan Francesco Loredano se venía a justificar, en primer lugar, como un reconocimiento a la fama del autor, calificado de insigne por la oratoria de la que había hecho gala. Pero, además, Eugenio de Miranda expone que se había inclinado por una de las obras del «más eloqüente Professor de la lengua Toscana» porque había querido «acreditar ser tanto más precisas las Impressiones propias en nuestros Reinos, quanto su idioma más fecundo, y rico de frases, pudiendo expressar las más graves y concisas de

46 AP, Sección Histórica, Tropas de la Casa Real, Archeros de la Noble Guarda de Corps, legajo 163, expediente «Disses, Pedro de» [1691].

47 Véase supra nota 40. En la dedicatoria a Oropesa que abre las Burlas (cit., sin foliar) Miranda indica escuetamente que «por haver yo cessado en la ocupación del Reyno, no se prosiguió».

48 MolL, Jaime, «Introducción» en Muestras de los nuevos punzones..., cit., p. ii.

49 "Occurrences of the types of Pedro Disses», en CRUICKSHANK, D.W.: "The types...», cit., pp. 87-90.

50. «Y Villadiego le ha comprado dos Moldes a dicho Pedro Disses, un juego de Matrizes, y algunos Punçones de otras, de que oy actualmente se está sirviendo en sus Fundiciones», «the Types...», cit., p. 74.

51 Representación de la Diputación de Reinos, Madrid, 11 de octubre de 1685, AHN, Consejos suprimidos, legajo 7157, 69.

52 Miranda y GamboA, E.: Dedicatoria al Conde de Oropesa, Burlas..., cit., ๆףv.

Hispania, LXV/3, núm. 221 (2005) 957-972 
los Estrangeros con mayor dulçura, y en estilo más Áthico" ${ }^{53}$. De esta forma, las impresiones propias de Pedro de Disses pasan a vincularse con la defensa y el elogio de la lengua propia y, lo que es más, de una academia de autores que era particular también.

En la hojarasca de aprobaciones, dedicatorias y demás paratextos que, como era habitual, abren el volumen de 1688 se encuentra una epístola de Miguel de Guevara en la que la traducción de Miranda era alabada porque en ella se hábía «seguido la cultura de los Españoles». Casi a la altura de la última década del siglo xvii, no es fácil llegar a determinar qué se podía entender exactamente por cultura de los españoles, una supuesta realidad que, además, cabía seguir $^{54}$, aunque parece tener que ver con el hecho de que la traducción de Miranda había añadido al original del académico Incognito veneciano la «variedad amena, y deleytosa» que al estilo de los autores españoles les sería propia ${ }^{55}$.

La epístola de Guevara se deshace en elogios de la obra, su artífice y de su traductor, no pudiendo «omitir el rendimiento de gracias que en nombre de nuestra Lengua, y Nación se debe dar a V.m.» por haber introducido «en España la Imprenta con Caracteres y Moldes propios». Ahora, España podría gloriarse de ser una Nueva Minerva y, con ella, «la numerosa Academia de los Doctos; pues tiene nativa en su País Imprenta, Caracteres, y Moldes proprios, sin mendigarlos de los estraños: cultivo que necessitava para ópima tarea de su fertilidad». En suma, se había logrado tener «Español a Loredano, Español el Idioma, Español el Molde, Española la Letra y Española también la Eloqüencia»s6.

El reiterado uso del calificativo español, tan frecuente en otros textos relacionados con la nueva fábrica de letra de 1685 , es aquí especialmente insistente y muy expresivo. La letra de Disses sería española por ser fabricada en la corte de su Monarquía y no importada, de la misma forma que las impresiones hechas con sus tipos serían propias en idéntico sentido. De hecho, como mostró Cruickshank, las letras de Pedro de Disses eran, ante todo, copias, bien del espécimen de las prensas vaticanas de 1628 , bien de los tipos diseñados originalmente por Hendrik van den Keere en el siglo xvi ${ }^{57}$.

Conviene destacar que no hemos encontrado testimonios de una voluntad de crear en 1685-1688 un diseño de letra española particularizado gráficamente a partir de una reflexión sobre una singular tradición escrituraria, como, por ejemplo, sí hará Ceferí Gorchs dos siglos más tarde ${ }^{58}$. Entonces, el impresor catalán, interesado "por cuanto ayuda a la típica fisonomía de nuestro país, en

\footnotetext{
53 Ibidem.

54 Cfr. PÉREZ MAGALLÓN, Jesús, Construyendo la modernidad. La cultura española en el tiempo de los novatores (1675-1725), Madrid, 2002; y ÁlvAREZ DE MIRANDA, P.: Palabras e ideas..., cit., pp. 384-401.

ss GuevarA, Miguel de, "Al Traductor» en Burlas de fortuna..., cit., sin foliar.

56 Idem., Id., cit., sin foliar.

57 «The types...», cit., p. 83.

58 La evocación de Alemania y la gótica es obvia. Cfr. BAIN, Peter, y SHAw, Paul (coords.): La letra gótica: tipo e identidad nacional, Valencia, 2001.
} 
todos los órdenes de la inteligencia y de la actividad humanas», confeccionó unos tipos de imprenta a partir de la bastarda española que quería restaurar a través de las prensas. Ya en 1888, la obra primogénița impresa con los nuevos tipos fue una antología de fragmentos «en los idiomas y dialectos usados en la Península Ibérica», de Cervantes a Herculano, pasando por Rosalía de Castro, Verdaguer y el Ipararraguirre del Gernikako Arbola ${ }^{59}$.

Pero volviendo a las Burlas de la fortuna de 1688, en otro de los paratextos que las acompañan, Manuel de Guerra y Rivera insiste en la vinculación de los nuevos caracteres tipográficos con la satisfacción de un deseo largamente ansiado por los estudiosos y escritores naturales, en suma, aquella Milicia Literaria de la que también hablaba Miranda en el antes citado elogio de la imprenta. Los nuevos instrumentos les permitirían no tener que enviar sus obras al extranjero para que fueran editadas con perfección, dadas las muchas dificultades que para lograrlo representaban las carencias materiales de la imprenta propia. El fraile trinitario proclama, entonces, que:

«Digno empleo del público, juzgarán los Literatos algún soberano aliento, que buelva a animar su noble intención, para que no busque España quien la eternize de fuera: y pues abunda en tantas fecundas Plumas de Escritores, no sea tan ingrata la Patria a sus desvelos, que los obligue a buscar forasteras Oficinas para hazerse immortales ${ }^{60}$.

Ofreciendo caracteres propios - letras y moldes españoles con Guevara-, la nueva fábrica tipográfica de Pedro de Disses vendría a servir a la voluntad de esa academia de doctos que eternizarían a España haciéndose inmortales ellos mismos a través de la imprenta. Por su parte, Jerónimo Pérez de la Morena no dudará en forjar una alianza entre los nuevos caracteres tipográficos propios y la posibilidad de que se oyera «la voz de las Ciencias, que tanto florecen en los Españoles», siendo «acusación de nuestra pereza, fuesse tan Estrangero su sonido» como hasta entonces lo había sido ${ }^{61}$.

Con su insistencia en que, por fin, se podría oír la voz de las ciencias de los españoles, al amparo de la comparación entre sus impresiones. y las posibilidades

59 GORCHS, Ceferí: Colección de trozos selectos en los idiomas y dialectos usados en la Peninsula lbérica impresa con los nuevos tipos de la bastarda española, Barcelona, 1888. Las citas provienen de la dedicatoria "A la Real Academia Española", bajo cuyo amparo se puso la iniciativa. Los autores elegidos fueron Cervantes, Luis de León, Calderón de la Barca y Núñez de Arce, para el castellano; Rosalía y Alberto Camino, para el gallego; José Caveda para el bable; Camões y Herculano, para el portugués; Vidal de Valenciano, Víctor Balaguer, Verdaguer y Frederic Soler, para el catalán; Teodor Llorente, para el valenciano; Marià Aguiló, para el mallorquín; y José M. de Iparraguirre y Arturo Campión, para el «euskaro».

60 GUERRA Y RIVERA, Manuel de: «Aprobación» en LOREDANO, G.F.: Burlas de la fortuna..., cit., sin foliar.

61 PÉREZ DE LA MORENA, Jerónimo: "Aprobación» en LOREDANO, G.F.: Burlas de la fortuna..., cit., sin foliar.

Hispania, LXV/3, núm. 221 (2005) 957-972 
materiales de hacer brillar su talento que éstas les brindan a unos y a otros, no poco de emulación entre autores naturales y extranjeros hay en los textos de Miranda, Guevara, Guerra o Pérez de la Morena que acompañaban las Burlas de 1688.

Desde el punto de vista de la construcción de una memoria de nación española, resultaría del mayor interés prestar atención a la particular contribución que a ella pudieron hacer autores y escritores. Como se sabe, el grupo de los hombres de letras desarrolló desde muy pronto un alto grado de autopercepción, tanto desde la perspectiva de la erección de privativos parnasos de «naturales», a los que acceder de manera jerárquica en atención al reconocimiento obtenido, como desde el punto de vista del parangón que se establecía con otras particulares repúblicas de «extranjeros» dentro de la gran República de las Letras internacional.

De las semblanzas de la renacentista Apologia pro adserenda Hispanorum eruditione de Alfonso García de Matamoros ${ }^{62}$ y la ideal biblioteca de autores hispanos que figuran en el anónimo Catalogus librorum bispanicorum ${ }^{63}$ o los Varones y bombres doctos, eminentes e insignes en letras naturales de España de Gabriel Lobo Lasso de la Vega ${ }^{64}$, ambos de la primera década del xvii, es fácil llegar a las voces de la Bibliotheca Hispana sive Hispanorum de Nicolás Antonio ${ }^{65}$. En ésta se condensaba una voluntad erudita de restaurar la reputación hispana por medio de la bibliografía que puede seguirse, superando el cambio de siglo y de dinastía, a través de la centuria siguiente.

A mediados de la década de 1670 , coincidiendo con la mayoría de edad del monarca, la magna obra de Antonio fue asentada en el memoria de los libros que debía tener en su despacho un adolescente rey Carlos $\mathrm{II}^{66}$. Lo hizo como la «Bibliotheca de España» ${ }^{67}$. No quedaba mucho para que llegase la hora de una letra de España gracias a la nueva fábrica tipográfica de Pedro de Disses, recibida por los autores naturales como la posibilidad de que toda una Monarquía descansase sobre el maravilloso don de la imprenta.

62 Edición, estudio, traducción y notas de José López de Toro. Madrid, 1943.

63 CÁtedra, Pedro: «La biblioteca y los escritos deseados (España, c. 1605)» en El libro antiguo español. V. El escrito en el Siglo de Oro. Prácticas y representaciones. Edición al cuidado de Javier Guijarro Ceballos, Salamanca, 1998, pp. 43-68.

64 Lobo Lasso no llegó a publicar esta obra, conservada en varios manuscritos, que en el inventario de su propia biblioteca se reseñaba como «Los poetas famosos antiguos, cronistas, historiadores y oradores españoles que a avido en el mundo y en el ynperio romano quando floreció, los nombres y patria dellos y de muchos de los modernos que han dado a la estanpa sus obras". Nos ocupamos de esta cuestión en "¿Cuánto vale una octava rima en verso heroico? La escritura de El caballero del Sayal y otras noticias sobre Gabriel Lobo Lasso de la Vega", en prensa.

65 Véase GÉAL, François: Figures de la bibliothèque dans l'imaginaire espagnol au Siècle d'Or, Paris, 1999.

66 Figura así en la Memoria de los libros del quarto del Rey Nuestro Señor (Dios le guarde), AHN, Consejos suprimidos, Legajo 7350.

67 Los dos volúmenes de la edición romana de 1672 se registraron como «Otro libro en latín que se intitula Biblioteca de Spaña» y «Otro en latín que también se intitula Bibliotheca de España», Ibidem. 